Bol. Mus. Para. Emilio Goeldi. Ciências Naturais, Belém, v. 1, n. 2, p. 147-162, maio-ago. 2006

\title{
Los camélidos fósiles del sitio Toca da Esperança, Bahia, Brasil Camelids fossils from sitio Toca da Esperança, Bahia, Brasil
}

Alfredo José Altamirano I

Resumen: El sitio Toca da Esperança, Bahia, es un yacimiento paleontológico que presenta restos de camélidos fósiles con datación del Pleistoceno Medio, entre 295,000 y 250,000 años A.P. La presencia de estos mamíferos permite interpretar sobre la filogenia del Paleolama weddeli y Lama, en el ambiente del Pleistoceno y hurgar aspectos del problema de la ocupación humana. A partir de las observaciones de alteraciones óseas como fracturas, desgastes, marcas de mordedura, incineraciones y ausencia de marcas de corte indican alteraciones tafonómicas y secundariamente antrópicas. Las aparentes formas quemadas son producto de hongos y líquenes que ennegrecen este material. Además, inundaciones y animales carnívoros produjeron fracturas transversales y angulares en los huesos de estos rumiantes y roedores efectuaron desgastes que aparentemente podrían ser confundidas como marcas dejadas por herramientas.

Palabras claves: Camélido fósil. Paleozoología. Brasil. Tafonomía. Filogenia. Pleistoceno.

Resumo: $\bigcirc$ sítio Toca da Esperança, Bahia, é um sítio paleontológico que apresenta restos de camelídeos fósseis com datação do Pleistoceno Médio, entre 295,000 e 250,000 anos A.P. para a camada IV. A evidência destes mamíferos permite interpretar a filogenia de Paleolama weddeli e Lama, no ambiente do Pleistoceno e fornece dados para esclarecer a questão da ocupação humana. As observações de alterações ósseas como fraturas, desgastes, marcas de mordedura, incinerações e ausência de marcas de corte indicam alterações tafonômicas e secundariamente antrópicas. As aparentes marcas de fogo são produto de fungos e líquens que enegrecem este material. Enquanto enchentes e animais carnívoros produziram fraturas transversais e angulares nos ossos destes ruminantes, roedores produziram os sinais que aparentemente poderiam ser confundidas com marcas produzidas por ferramentas.

Palavras-chave: Camelídeo fóssil. Paleozoologia. Brasil. Tafonomia. Filogenia. Pleistoceno.

I Universidade Federal do Estado do Rio de Janeiro. Departamento de Filosofia e Ciências Sociais. Arqueólogo. Rio de Janeiro, Rio de Janeiro, Brasil (altamirano@pesquisador.cnpq.br).

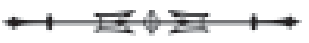




\section{INTRODUCCION}

Uno de los principales mamíferos autóctonos de América del Sur es el camélido andino y cuyo origen sucedió en la extensa meseta de la región neo-ártica de los Estados Unidos de Norteamérica (BONAVIA, 1996; SIMPSON, 1945). Actualmente la familia de los Camelidae comprende dos grupos: los camélidos del Viejo Mundo subdivididos por el camello o bactriano (Camel camelus) y el dromedario (Camel dromedarius); y los del Nuevo Mundo compuesto por la alpaca (Lama pacos), la llama (Lama glama), la vicuña (Lama vicugna) y el guanaco (Lama guanicoe). Los primeros se concentran en los países árabes y los segundos, en los países andinos (PIRES-FERREIRA, 1982; STANLEY; KADWELL; WHEELER, 2000; SUMAR, 1992). Sin embargo, algunos autores tradicionales todavía consideran a la vicuña (Vicugna vicugna) como una subespecie diferente de Lama debido a las características peculiares de los incisivos de raíz abierta y de crecimiento continuo (PAULA COUTO, 1979).

Los objetivos de este trabajo fueron analizar el material óseo de camélidos fósiles procedente de uno de los sitios arqueológicos más controvertidos de la arqueología brasileña y americana, y inferir la discutida presencia humana en ese sitio. La metodología utilizada fue la observación macroscópica fina del material óseo, concentrada principalmente en algunos rasgos y alteraciones estructurales como el tipo de fractura, desgaste, mordedura, ennegrecido y el tejido esponjoso, lo que nos podría conducir a resolver si tales alteraciones fueron efectuadas por la presencia humana o por factores tafonómicos (animales carnívoros, microorganismos y el medio ambiente).
El sitio Toca da Esperança, descubierto en 1982, está localizado en la región de Central, estado de Bahia, nordeste del Brasil (BELTRÃO, 1993). Tiene una extensión de casi $270.000 \mathrm{~km}^{2}$ donde se concentra una vegetación autóctona llamada caatinga1. El sitio consiste de un conjunto de dos grutas que se localizan en el municipio de Central (11 ${ }^{\circ} 2^{\prime}$ S. y $42^{\circ} 7^{\prime} \mathrm{W}$ ), en la hacienda Pé do Morro excavadas en los calcáreos de la Serra Preta o Serra Brava, a 672 m sobre el nivel del mar. Este sitio ha producido grande polémica en torno a su antigüedad y asociación con la presencia humana, principalmente el Homo erectus, datando desde 300,000 años AP. periodo Pleistoceno Medio (BELTRÃO et al., 1991; LUMLEY et al., 1988) (Figura 1).

Beltrão y Locks (1989) realizaron un estudio paleozoológico preliminar del sitio Toca da Esperança e identificaron varios grupos como paleo-llama (Palaeolama major), megaterio (Eremotherium laurillardi), armadillos grandes (Pampatherium humboldti, Propraopus sulcatus), gliptodonte (Panochthus panochthus), caballo (Hippidium principale), tigre diente de sable (Smilodon populator populator), roedores cávidos (cuy silvestre o preá) y cricétidos. Este material procedió de la cuadrícula 2, capa 4 y sobre el grupo Paleolama solamente revisaron 32 fragmentos óseos. Por otro lado, el sitio posee dos tipos de dataciones: carbono 14 (C14) y tório/uranio (Th/ $\mathrm{U})$, empleándose este último para dataciones de mayor alcance de 10.000 años de antigüedad. Así, indicó que la capa II y IV poseen edades entre $204.000 \pm 34.000$ y 26.000 A.P., $295.000 \pm 78.000$ y 80.000 A.P. Conteniendo esta última capa dos sub-niveles: IVb (295.000250.000 AP.) y Va (250.000-210.000 AP.). Además,

\footnotetext{
1 Es una formación de vegetales xerófilas, pobre y hostil, constituida de espinas, pequeños árboles de hojas finas, hierbas duras, cardos y gravatás. Esta vegetación se localiza en el nordeste brasileiro, entre la selva amazónica y la zona de los campos. Se presenta como una floresta de árboles pequeños y tortuosos, y rica en cactáceas, y también como una escasa vegetación rastrera. Las plantas más frecuentes son el Xique-xique, la macambira, catingueira, jurema, umburana, marmeleiro, umbu y el facheiro (ENCICLOPEDIA DELTA LAROUSSE, 1970).
}

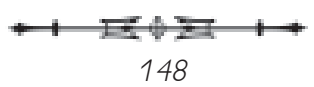




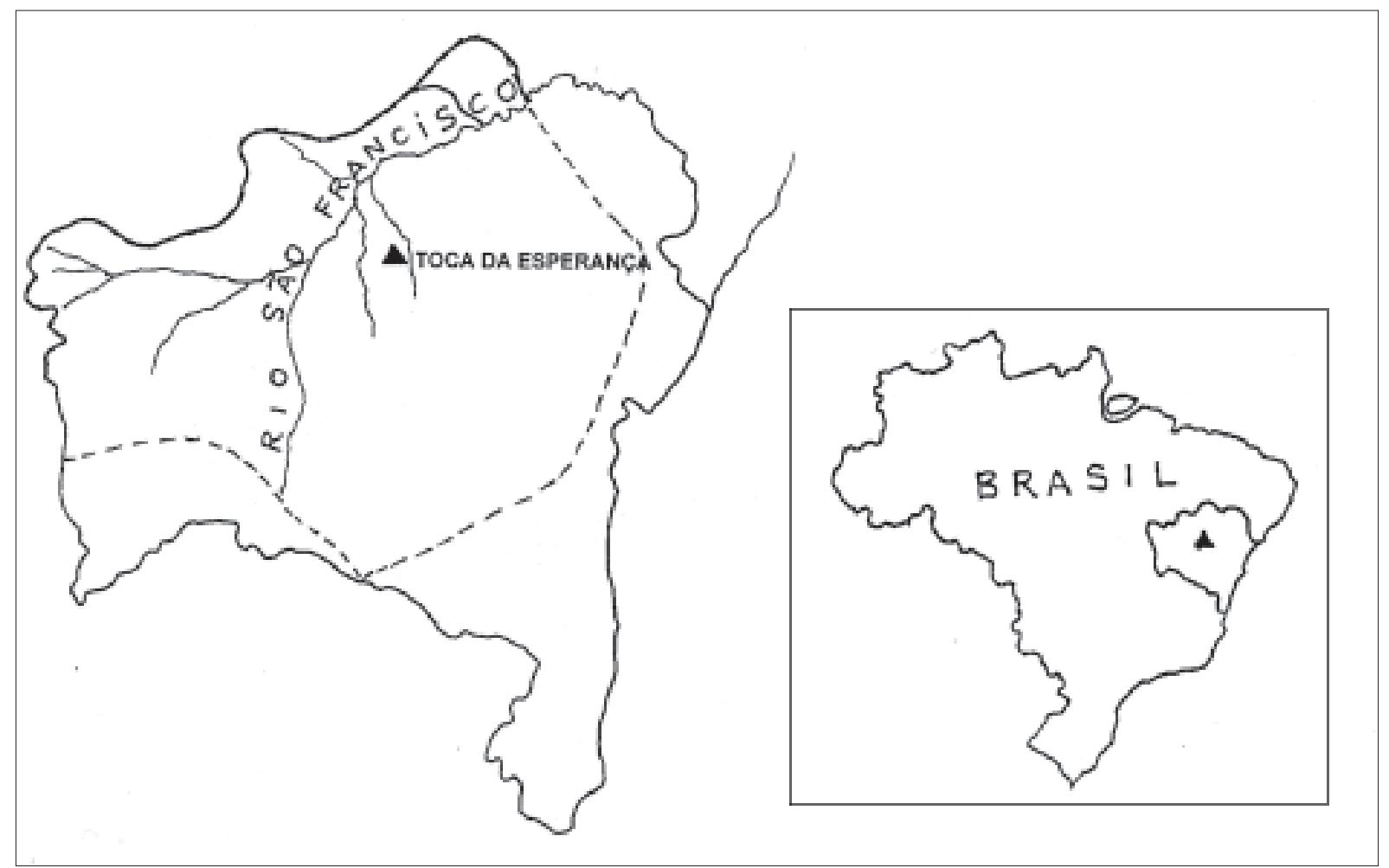

Figura 1. Localización del sitio Toca da Esperança, Bahia, Brasil.

esta capa $\mathrm{N}$ es la que produjo mayor cantidad de restos óseos y dientes de camélidos y otros animales extintos (BELTRÃO et al., 1987; BELTRÃO, 1993).

Los fósiles son fundamentalmente de Paleolama weddeli, que llegaron a Bahia entre 295.000 y 260.000 AP. aproximadamente. En el contexto paleontológico de América del Sur, el género Paleolama, según Paula Couto (1979), estaba conformado de tres especies: Paleolama weddeli, Paleolama crassa y Paleolama aequatorialis, siendo englobado el $P$. major dentro del $P$. weddeli. Sus restos fósiles se encuentran ampliamente distribuidos en los estados de Acre, Bahia, Amazonas, Minas Gerais, Paraíba, Piauí, Rio de Janeiro, Rio Grande do Sul y Sergipe, y vivieron hasta fines del Pleistoceno Tardío (100.000 - 10.000 AP.) (CARTELLE, 1983; DANTAS, 2003; GUERIN et al., 1999). Actualmente la importancia de los camélidos radica en el establecimiento de programas de readaptación en las antiguas áreas que vivieron para el beneficio del turismo regional y la producción de trabajo artesanal y textil (WHEELER, 2000). Asimismo, la reconstrucción de la historia evolutiva de este grupo y su actual distribución geográfica constituyen los temas más relevantes de la historia de la Paleontología americana.

\section{MATERIAL Y METODOS}

El material está conformado por 36 huesos y 6 dientes de camélidos (Tabla 1) (Anexo 1) existente en el gabinete de arqueología del Museo Nacional de la Universidad Federal do Rio de Janeiro, sito en la Quinta de Boa Vista, São Cristovão, y fue analizado

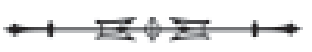


entre el 21 de mayo de 1997 al 11 junio del mismo año. La mayoría del material colectado se encuentra fragmentado. Los huesos y dientes fueron lavados, colados, marcados e identificados, con auxíio de la bibliografía especializada disponible.

El método utilizado para la identificación de especie fue la osteología comparada. Fue empleado un esqueleto completo de alpaca y un manual osteológico ilustrado de camélidos sudamericanos (PACHECO; ALTAMIRANO; GUERRA, 1986; WEBB, 1974). La descripción de cada hueso fue efectuada en fichas de investigación, indicando capa, número de registro, profundidad y la observación de las alteraciones morfológicas. Para la estimación de la edad fueron seguidos las recomendaciones dadas por Altamirano (1987), clasificando en tierno (0 - 7 meses), joven (8 meses - 4 años) y adulto (mayor de 4 años).

La determinación del sexo no fue posible ser establecida por la ausencia del material diagnóstico. Sin embargo, fueron observadas algunas rugosidades en las epífisis de los huesos largos como en la tibia, carpianos y tarsianos, indicando la posibilidad de animales machos (ALTAMIRANO, 1995; GRAYSON, 1983).

El análisis de las fracturas fue realizada según Grayson (Op. cit.) que las clasifica en cuatro tipos: concoidal, longitudinal, transversal y angular. La fractura concoidal es aquella que exhibe sinuosidad de borde cortante y causada por fuerte impacto de roca por mano humana para la extracción de la médula (BINFORD, 1985); la fractural longitudinal ocurre en huesos largos y producen una amplia abertura también para conseguir la medula. Para el caso de los camélidos, ambas son causadas básicamente por acción humana (ALTAMIRANO, 1995). Por otro lado, la fractura transversal es aquella que segmenta al hueso por la parte de la diáfisis y metáfisis; y las fracturas angulares son aquellas radiaciones que aparecen en el borde transversal causadas por mordidas de animales carnívoros (ALTAMIRANO, 1995). Estos últimos son propios de factores biológicos y tafonómicos. Pisadas de animales grandes e inundaciones acarreando piedras también producen este tipo de fracturas.

Tabla 1. Frecuencia de huesos del Palaeolama weddeli del sitio Toca da Esperança (Bahia, Brasil), según partes corporal y edad.

\begin{tabular}{lccc} 
Parte corporal & Joven & Adulto & Total \\
\hline Dientes & 3 & 3 & 6 \\
\hline Vértebras & - & 3 & 3 \\
Escápula & - & 1 & 1 \\
Húmero & - & 4 & 4 \\
Carpianos & - & 6 & 6 \\
Fémur & - & 1 & 1 \\
Tibia & 1 & - & 1 \\
Tarsianos & - & 8 & 8 \\
Metapodios & 3 & 5 & 8 \\
Falanges & 2 & 2 & 4 \\
Total & $9(21,5 \%)$ & $33(78,5 \%)$ & $42(100,0 \%)$ \\
\hline
\end{tabular}

\section{RESULTADOS}

En el sitio Toca da Esperança, Bahia, habían dos tipos de camélidos: Paleolama weddeli y Lama sp. El primero es de talla alta y el otro más pequeño. (Anexo 1).

La elevada frecuencia de metapodios, carpianos, tarsianos y falanges de camélidos adultos $(78,5 \%)$ y jóvenes (21,5\%), algunos con marcas de mordedura, revela que estos fueron capturados por animales carnívoros (Tabla 1) (Figura 2).

La presencia de huesos de las ancas, vértebras lumbares y torácicas, epífisis distal de húmero, fémur y miembros posteriores se concentran en la boca de la cueva y fueron allí mismo muertos y consumidos. Luego, los despojos fueron arrastrados, principalmente las patas, a áreas más elevadas de la cueva.

Sobre los dientes registramos tres fragmentos de un molar, superior derecho de llama (tamaño menor) joven de 3 años de edad, calcinados. Otro animal adulto, 3 fragmentos de segundo molar, superior, de más 5 años. También calcinado.

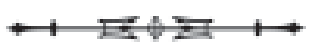


Existen marcas de mordedura de animales carnívoros y roedores en los bordes de los huesos largos y en el periostio.

Los huesos evidencian fracturas transversales y angulares causadas por fuerte mordedura de carnívoros para la extracción de las médulas (Figura 3).

El tejido óseo del paleolama es del tipo homogéneo y macro-poroso similar a la estructura de camélidos adaptados al litoral costeño peruano.

\section{DISCUSIÓN}

Nuestra discusión comprende tres puntos centrales: filogenia de los camélidos, si estos ungulados fueron consumidos por humanos o por animales carnívoros y sobre la asociación contextual del camélido en la región.

Después de las grandes mudanzas geográficas y climatológicas de la superficie del orbe y la formación de los actuales continentes, el orden de los ungulados fue aislado por barreras naturales y la línea de evolución de los camélidos continuó desde hace unos 50 millones de años, durante el período Eoceno Superior de la era Terciaria, apareciendo en

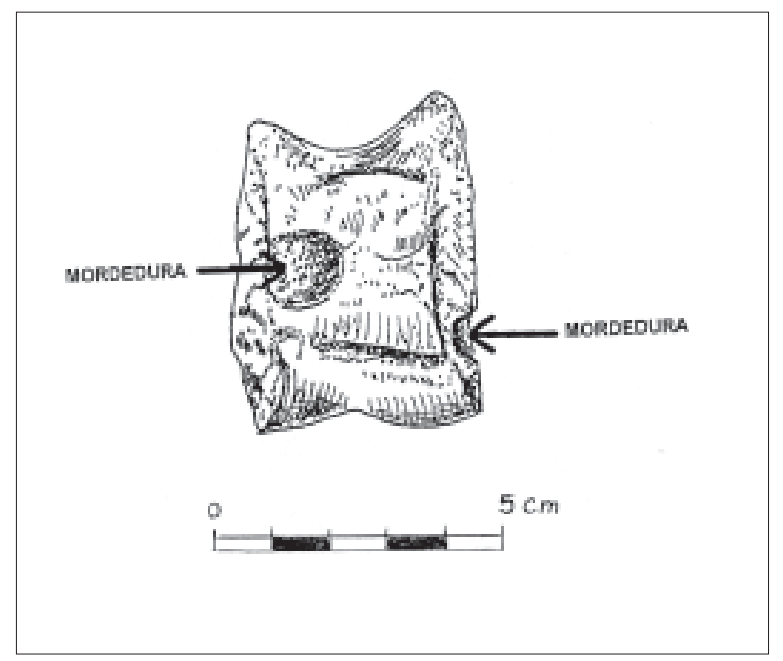

Figura 2. Tercer carpiano, primera falange y cuarto tarsiano de Paleolama weddeli, capa IV y números de registro 043, 059 y 069 del sitio Toca da Esperança (Bahia, Brasil). la meseta norteamericana desde La Florida hasta Los Angeles, un pequeño artiodáctilo llamado Protylopus. Era un animal de escasa estatura debido a sus extremidades cortas que remataban en cuatro dedos y con dientes en serie continua, careciendo de diastema, diferente de los primeros Pécora de aquellos tiempos (ALTAMIRANO, 1995; HOFFSTETTER, 1952; PAULA COUTO, 1979).

El Protylopus se mantuvo latente cerca de 8 millones de años durante el período Oligoceno, hace unos 35 millones años aproximadamente. Posteriormente dió origen a una nueva forma de mamífero, más evolucionado que habría sido el Pöebrotherium, animal que se caracterizó por la presencia de falanges reducidas lateralmente, persistiendo dos dedos, el segundo y el tercero; asimismo, en la mandíbula apareció un diastema o espacio interdental debido a la perdida del primer y segundo premolar; los huesos radio y cubito se fusionaron formando una sola pieza; los metacarpianos conservaron la superficie articular distal separada para la articulación con las primeras falanges (VALLENAS, 1970). Sin embargo, otras especies colaterales incrementaron proporciones importantes en su tamaño.

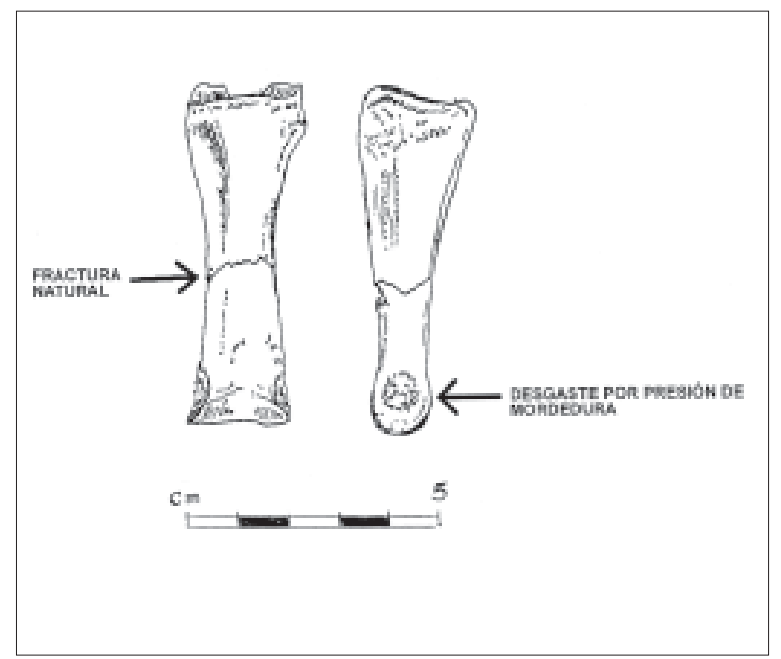

Figura 3. Astrágalo derecho de Paleolama weddeli del sitio Toca da Esperança (Bahia, Brasil), con muestra de mordedura de mamífero carnívoro. Procede de la capa N, Nºg. 117.

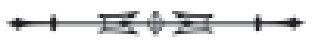


La evolución central del camélido continuó a través del Protomeryx, a fines del Oligoceno, que originó al Procamelus y al Pliauchenia, durante el Mioceno Temprano y Medio, hace unos 20 millones de años, sus fósiles aparecen distribuidos en la meseta de Norteamérica (FRANKLIN, 1982; PIRES-FERREIRA, 1982). Posteriormente, el Procamelus se desplazó a través del puente de Bering para dar origen al camello (Camelus bactrianus) y al dromedario (Camelus dromedarius), mientras que el grupo del Pliauchenia continuó ocupando las montañas rocosas de California y Florida de los EE.UU. (COLBERT, 1955; HOFFSTETTER, 1952). La dispersión geográfica del Procamelus hacia las frías estepas de Asia, cercano Oriente y los desiertos del norte de África habría ocurrido durante el Plioceno Tardío, hace unos 5 a 6 millones de años (FRANKLIN, 1982). Sin embargo, algunos autores plantean que el Pliauchenia dió origen al Procamelus (PIRESFERREIRA, 1982) y otros inversamente sostienen que el Procamelus generó al Pliauchenia (VALLENAS, 1970). Así, el problema paleontológico y cronológico entre el Pliauchenia, Procamelus y Protomeryx todavía se mantiene en discusión.

Los paleontólogos consideran que el género Pliauchenia (COPE, 1875), dió origen al género Hemiauchenia probablemente hacia fines del Plioceno o inicios del Pleistoceno, hace 1 ó 2 millones de años (FRANKLIN, 1982; GERVAIS; AMEGHINO, 1880; WEBB, 1974), cuyas características biológicas ya eran similares al de los camélidos actuales, desplazándose desde Norteamérica hacia los trópicos de Sudamérica ${ }^{2}$. Período que abarca el levantamiento del puente terrestre de Panamá, evento que permitió el paso de varias especies de mamíferos fósiles carnívoros y herbívoros a la América del Sur y viceversa. Al atravesar la cordillera de los Andes se estableció en las Pampas de Argentina y Tierra del Fuego, donde sus restos fósiles aparecen en los depósitos de Chapadmalalán y Uquián (GERVAIS, 1855; HOFFSTETTER, 1952).

Durante el período de las glaciaciones, Hemiauchenia evolucionó hacia dos formas conocidas: el Palaeolama y el Lama, adaptándose a un piso ecológico de sabana en extensas planicies. Así, las regiones vecinas a la Cordillera de los Andes habrían constituido la cuna de los actuales camélidos sudamericanos (PIRES-FERREIRA, 1982). Además, el Hemiauchenia y el Paleolama fueron camélidos gigantes que estaban bien adaptados al frío del Pleistoceno y a las mesetas bajas. Siendo el tamaño del esqueleto de Paleolama aproximadamente dos veces mayor que el de una llama actual.

El Paleolama se extendió desde el Sur, Este y Oeste de la cadena montañosa andina hasta las Pampas de Argentina (CABRERA, 1932, 1935; GERVAIS, 1855; LÓPEZ ARANGUREN, 1930; WEBB, 1974). Sobre la taxonomía se ha sugerido la presencia de tres especies: $P$. weddeli - que comprende a otros paleolamas como $P$. major, $P$. paradoxa, $P$. reissi y $P$. weddeli - , P. crassa y $P$. aequatorialis (PAULA COUTO, 1979). Restos fósiles de Paleolama weddeli (que engloba al P. major) han sido hallados en Bolivia (Tarija) (GERVAIS, 1855); en Uruguay; en los Estados de Acre, Amazonas, Bahia (Toca da Esperança, Toca dos Búzios, Gruta dos Brejões), Ceará, Paraíba, Pernambuco, Piauí, Minas Gerais (Lagoa Santa, Diamantina), Rio de Janeiro, São Paulo, Rio Grande do Sul y Sergipe en el Brasil; incluyendo las regiones altoandinas de la sierra central del Perú. El $P$. crassa aparece en la fase Chicheanense del Pleistoceno Medio de los Andes ecuatorianos y el $P$. aequatorialis en la fase Coralinense (La Coralina) y Punín de la costa ecuatoriana y en diversas cuevas

2 Los fósiles de América del Norte por su estrecha semejanza al de los camélidos sudamericanos se les ha denominado la "Llama del Pleistoceno de La Florida" (WEBB, 1974).

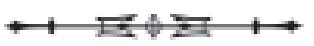


de las punas de Junín, Pasco y Huanuco en el Perú (DANTAS, 2003; HOFFSTETTER, 1952).

Por otro lado, el género Lama también surgió durante el Pleistoceno Medio, hace unos 500,000 años aproximadamente, adaptándose a un ambiente seco y ocupando casi toda la región meridional de los Andes. Los lamidos sobrevivieron al clima frío del Pleistoceno y durante el Holoceno se refugiaron en las alturas de la cordillera de los Andes centrales y la Patagonia. Así, el grupo Lama dió origen a 4 formas de camélidos conocidos: el guanaco, vicuña, llama y alpaca, y sus fósiles fueron recuperados en las pampas argentinas (PAULA COUTO, 1979) (Tabla 2).

En los depósitos pre-holocénicos de Argentina y Bolivia se hallaron las cuatro formas de Lama en estado silvestre y donde la llama y la alpaca de formas domesticadas tuvieron sus ancestros silvestres casi semejantes (LÓPEZ ARANGUREN, 1930). Esto contradice a la hipótesis de Herre, quien considera que tanto la llama como la alpaca provienen de cruces selectivos entre el guanaco y la vicuña (HERRE, 1952). Otros autores plantean la coexistencia de seis formas de Lamini diferentes durante el proceso de domesticación, estos fueron el guanaco, la vicuña, la llama silvestre, la llama domesticada, la alpaca silvestre y la alpaca domesticada (PAULA COUTO, 1979; PIRES-FERREIRA, 1982).

Hoy se acepta la hipótesis que los camellos y llamas actuales son descendientes de ancestros norteamericanos, pues, en el Terciario de NorteAmérica fueron hallados restos de una serie evolutiva continua de camélidos a partir de formas primitivas no especializadas. Esta serie comenzó a partir del período Eoceno, todavía con dentición placentaria completa y tetradactílicas, hasta las formas especializadas del Mioceno y Plioceno, de dentición más o menos reducida y didactilicas. Durante fines del Plioceno, camellos y llamas fósiles partieron del Norte de América en dos direcciones opuestas. Una, la más antigua apunta que los camellos se dirigieron para el norte y oeste, cruzando el puente terrestre de Bering y las islas Aleutianas hacia Rusia siberiana y, después, a las regiones asiáticas donde viven actualmente. Por otro lado, las llamas se dirigieron para América del Sur cuando se formó el puente terrestre de Panamá, entre 3 y 1 millón de años, ocupando las extensas planicies del Amazonas, cubiertas de sabanas y posteriormente durante el Holoceno se adaptaron a las mesetas altoandinas donde viven hasta hoy (FRANKLIN, 1982; WEBB, 1974).

Tabla 2. Relación taxonómica de los camélidos de América del Sur, entre el Pleistoceno Medio (300,000-100,000 AP) hasta el Reciente (10,000 AP- actual). Tomado de Paula Couto (1979), Cartelle (1983), Guerin et al (1999) y Dantas (2003). (E) = extinto.

\begin{tabular}{|c|c|c|c|}
\hline $\begin{array}{l}\text { Género de Camélidos } \\
\text { Sudamericanos }\end{array}$ & Hoffstetter (1952) & $\begin{array}{l}\text { Cabrera }(1935,1932), \\
\text { Paula Couto }(1979)\end{array}$ & Distribución Geográfcca \\
\hline \multirow{2}{*}{$\begin{array}{l}\text { Palaeolama } \\
\text { (Gervais, 1867) } \\
\text { Todos extintos (E) }\end{array}$} & $\begin{array}{l}\text { P. major } \\
\text { P. paradoxa } \\
\text { P. reissi } \\
\text { P. weddeli }\end{array}$ & P. weddeli & $\begin{array}{l}\text { Argentina, Brasil (Acre, Amazonas, Bahia, Ceará, Paraíba, } \\
\text { Piauí, Minas Gerais, Rio Grande do Sul, Pernambuco, } \\
\text { Sergipe), Bolivia, Chile, Ecuador, Perú }\end{array}$ \\
\hline & $\begin{array}{l}\text { P. crassa } \\
\text { P. aequatorialis }\end{array}$ & $\begin{array}{l}\text { P. crassa } \\
\text { P. aequatorialis }\end{array}$ & $\begin{array}{l}\text { Andes ecuatorianos } \\
\text { Costa del Ecuador }\end{array}$ \\
\hline $\begin{array}{l}\text { Lama } \\
\text { (Frisch, 1775) }\end{array}$ & & $\begin{array}{l}\text { L. oweni }(\mathrm{E}) \\
\text { L. augustimaxila }(\mathrm{E}) \\
\text { L. glama } \\
\text { L. guanicoe } \\
\text { L. pacos } \\
\text { L. vicugna }\end{array}$ & $\begin{array}{l}\text { Argentina } \\
\text { Argentina y Bolivia } \\
\text { Bolivia, Chile, Ecuador y Perú } \\
\text { Argentina, Bolivia, Chile, Ecuador y Perú } \\
\text { Bolivia, Ecuador y Perú } \\
\text { Bolivia, Chile, Ecuador y Perú }\end{array}$ \\
\hline
\end{tabular}

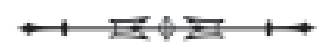


El paso de los camellos por Canadá, Alaska, Bering y Siberia puede indicar que en estas tierras - durante fines del Plioceno e inicios del Pleistoceno - floreció un clima ameno, agradable y con pastos frescos. Lo que permitió la migración buscando tierras bajas de climas cálidos cuando comenzaba el período de las grandes glaciaciones. Al contrario, las llamas se adaptaron primero a tierras bajas de clima frío (Brasil y Argentina) y durante el Holoceno se concentraron en la cordillera de los Andes, hasta el límite de las nieves, desde el Ecuador, Perú, Bolivia, Paraguay y Argentina hasta el sur de Patagonia y Chile (BONAVIA, 1996; WEBB, 1974).

La existencia de cruces libres entre los camélidos ocurre frecuentemente en los estados silvestres y aún entre los domesticados, resultando 16 posibilidades de éxito en la reproducción. Esta característica genética ha sucedido desde tiempos remotos como consecuencia de los 74 cromosomas diploides, tanto en las especies puras como en las híbridas (BUSTINZA, 1970; BUSTINZA; MALASPINA, 1970). En el año 2000, en el Centro de Reproducción de Camellos en Dubai, Arabia Saudita, nació un híbrido de padre dromedario y madre llama, que denominaron de Kamilah, mas no existen estudios al respecto (Revista Dominical Globo, junio de 2000). Sin embargo, los paleontólogos y paleozoólogos de camélidos no han tenido cuidado en considerar este problema genético para explicar la filogenia.

El sitio Toca da Esperança fue excavado en tres campañas: 1986, 1987 y 1989. La profundidad del depósito es de 1 a $1,5 \mathrm{~m}$, pero las 4 capas han proporcionado extraordinarios fechados,

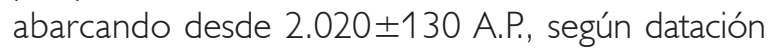
radiocarbónica para el nivel I, y hasta 295.000 años para la capa IV (método Th/U). La espectrometría del rayo gama, realizado por Gif-sur-yvette, y la espectrometría del rayo alfa realizado en Los Angeles y en Menlo Park parecen mostrar buenas concordancias. No obstante, estas dataciones fueron hechos en base a 3 huesos de fósiles discretos
(LYNCH, 1991a). La fauna procedente de los niveles III y $\mathrm{N}$, incluyen paleo-llama (Palaeolama major), megaterio (Eremotherium laurillardi), armadillos grandes (Pampatherium humboldti, Propraopus sulcatus), gliptodonte (Panochthus panochthus), caballo (Hippidium principale), tigre diente de sable (Smilodon populator populator), roedores cávidos (cuy silvestre o preá) y cricétidos (BELTRÃO; LOCKS, 1989).

Existen dos posiciones alternativas sobre este problema. Un grupo franco-brasileño defiende la presencia del Homo erectus del Pleistoceno Medio hace 300 mil años (BELTRÃO; LOCKS, 1989; LUMLEY et al., 1988) y otro conformado por los céticos norteamericanos y algunos arqueólogos brasileños que niegan esta posición y admiten dataciones máximas de 11,500 a.C. (LYNCH, 1991a, 1991b; PROUS, 1992; SANDERS; MARINO, 1971). El problema está en la falta de mayor contundencia de la evidencia y frecuencia de la cultura material asociado con los fósiles extintos. Así, Beltrão (1993) refiere:

Na camada C N foi achado um chopper, além de 'chips' em quartzo e quartzito com retoques profundos ou invasivos. Alasca tipo 'clactoniano' e o chopper foram submetidos ao estudo de traceologia em Paris.

En esta pesquisa, la frecuencia de falanges, carpianos y tarsianos de camélidos jóvenes y adultos de la capa IV (20 piezas y fragmentos) y huellas de mordedura de animales carnívoros son indicadores indirectos de caza. Empero, los huesos no evidencian marcas de corte ni fracturas concoidales/longitudinales que justifiquen la presencia humana. Tampoco fueron encontrados los huesos del cráneo, la mandíbula, pelvis y sacro. Quizá estos huesos planos por su fragilidad se deterioró y se perdió durante el prolongado tiempo y humedad de la cueva. Tampoco existen paleolamas tiernos que indiquen una preferencia por animales de esta edad. Los despojos de carne, incluyendo patas, distal de húmeros, carpianos y tarsianos, fueron transportados

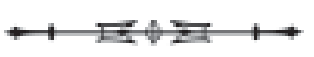


a la cueva, ubicada a unos 12 metros de altitud, y allí fueron mordidos, fracturados y abandonados. La escasa evidencia cultural no es suficiente para defender la hipótesis de la antigüedad humana en este período.

En el período paleoindio americano no existe otro sitio arqueológico con la enorme antigüedad de 300 mil años que pueda dar sustento para entender la dispersión del hombre que se desplazaba desde el Viejo Mundo a América (FAGAN, 1987). Los sitios arqueológicos más antiguos del Brasil son Pedra Furada en São Raimondo Nonato (Piauí), Toca do sitio do Meio (Piauí), Chã do Caboclo (Pernambuco), Lapa dos Brejões (Bahia), Lagoa Santa y Lapa Vermelha IV (Minas Gerais), Alice Böer (São Paulo), Lapa do Sol (Mato Grosso) y Serranópolis (Goiás), entre otros (GUIDON, 1984, 1988; PROUS, 1992) y Monte Verde en Chile (DILLEHAY, 1988) con antigüedades que oscilan entre 10 y 35 mil años. Además, estos sitios, una vez descubiertos, provocaron controversias e discusiones. Esto es normal en todo proceso científico. Además, las informaciones son escasas y controvertidas en la medida que retrocedemos en el tiempo. Solamente a través de un contexto arqueológico intacto y un correcto análisis de laboratorio del material biológico pueden conducirnos a resultados valiosos y convincentes para el avance de esta disciplina.

Por otro lado, el sitio Gruta dos Brejões, en Bahia, contemporáneo de Toca da Esperança, estudiado por Cartelle (1983) también encontró los mismos animales fósiles identificados por Beltrão y Locks (1989), además de uñas, pelos, coprolitos y huesos de Paleolama sp. y megaterio (Nothrotherium maquinensis). Cartelle (Op. cit.) sugirió que los camélidos poseen un comportamiento gregario, prefiriendo campos abiertos o explanadas y no se refugiaban en la cueva. Por este motivo, admitió la hipótesis que en aquellos lugares deben haber ocurrido inundaciones periódicas porque los huesos fueron transportados dentro de los salones de la cueva y que hasta la actualidad todavía continua ocurriendo inundaciones repentinas donde mueren ovejas y cabras de los rebaños de los campesinos de la región. Allí encontraron la muerte, impedidos de retornar por las aguas y perdidos por la oscuridad de la cueva.

Los huesos evidencian haber sido fuertemente mordidos produciendo fracturas transversales y angulares para la extracción del tuétano. Empero, este comportamiento etológico parece haber sido causado por animales carnívoros detectándose marcas de mordedura y fractura natural por acción biológica, tal como sucedió con el astrágalo derecho y las epífisis distal de húmeros de Paleolama weddeli y Lama sp., constituyendo una fuerte evidencia de tafonomía (Figura 4). Es decir, los huesos fueron transportados por animales carnívoros.

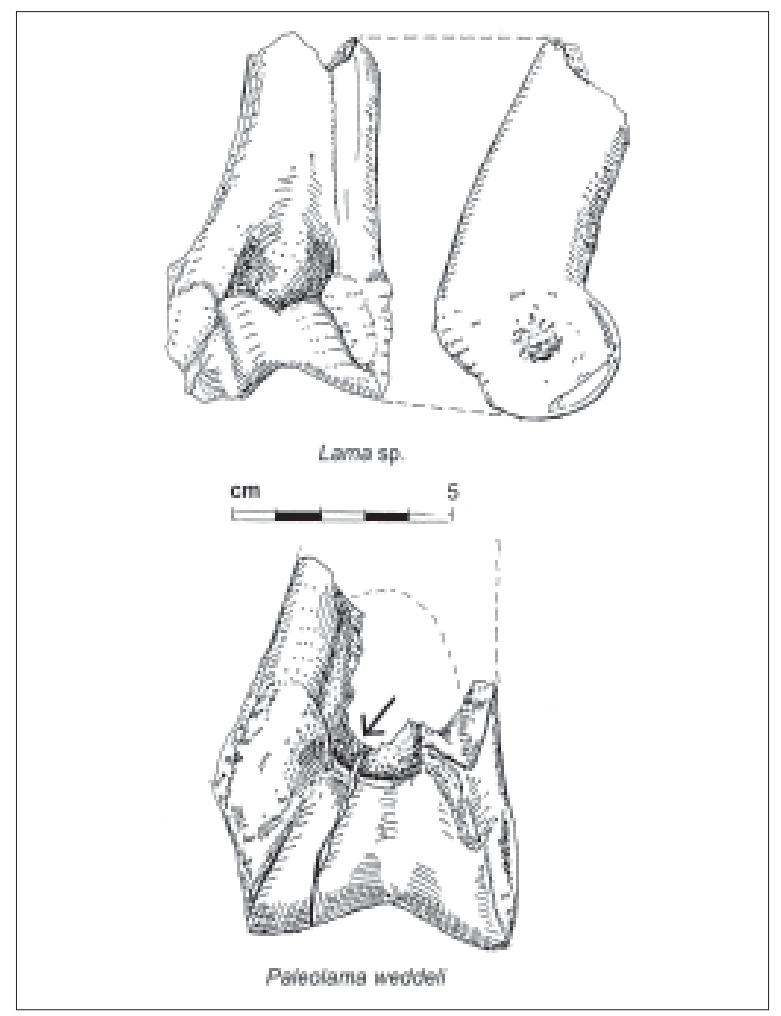

Figura 4. Fractura transversal de la epífisis distal de húmeros izquierdos de ejemplares de Paleolama weddeli y Lama sp., adultos, sitio de la Toca da Esperança, Bahia, Brasil. Proceden de la capa $\mathrm{N}, \mathrm{N}^{\circ}$ reg. 042, 106 y 048.

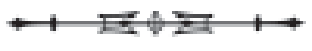


Sin embargo, el equipo franco-brasileño reconoció 2 pebble tools y 1 chopper del nivel $\mathrm{N}$, añadiendo un martillo de piedra y varias lascas de los niveles II y $\mathbb{N}$. Los diseños lineares de las herramientas sugieren que ellos son rudimentarios. También, Beltrão y Danon (1987) lanzan una hipótesis más arriesgada, sugiriendo que al menos uno de ellos se parece al estilo clactoniano. Asimismo, comentan de molduras dentarias humanas, herramientas óseas, estructuras de fogones y caracoles que aparecen en todos los niveles. Además, Beltrão y Danon (op. cit.) especifican que los artefactos de cuarzo y cuarcita proceden de una cantera localizada a $10 \mathrm{~km}$ de distancia. El depósito consiste de una capa delgada y los artefactos son simples, golpeadas sólo en una cara de estos y faltan registros completos. Por tanto, Lynch (1991 b) refuta severamente las ideas de Beltrão y Danon, y sugiere que la evidencia es débil para sostener la hipótesis del hombre (Homo erectus?) del Pleistoceno Medio en esta parte de la América del Sur.

No obstante, existe mucha controversia acerca del hombre del Pleistoceno Medio, específicamente el hombre de Pekin, indicando que este ya poseía el uso sistemático del fuego, el cual es considerado de haber estado presente en la Toca da Esperança y su uso era necesario para el pasaje beringiano (BINFORD, 1985). Si verificado esto, el descubrimiento de Toca da Esperança tendría implicancias para la arqueología tanto del Nuevo como del Viejo Mundo. Sin embargo, algunas rocas de cuarzo pueden ser pseudotool tal como ocurre en lugares donde cruzaron muchos animales de porte grande, sitios inundados (CARTELLE, 1983) y encontradas en ese contexto podrían conducir a inferencias erróneas.

Otra observación es que aparentemente la mayoría de huesos parece haber sido quemado. Sin embargo, algunos hongos y líquenes que poseen abundante lignito y óxido de manganeso también puede obscurecer al hueso fósil, en época de mucha humedad (inundaciones), dando cierta confusión de haber sido quemado. Además, quemadas naturales ocurren frecuentemente en sitios de pasto seco, o sea, en épocas de intensa sequía del Brasil Central. Esta tafonomía biótica es frecuente en el estudio de huesos de clima tropical (GOMIDE, 1999). Otra observación es que los huesos analizados no indican la existencia de marcas de corte. Todo parece apuntar que los restos óseos de camélidos de la capa $\mathrm{N}$ no fueron tocados por mano humana y podrían haber sido transportados por animales carnívoros como por ejemplo el tigre diente de sable (Smilodon populator populator) que ya vivía en aquel período.

Sobre las posibles herramientas óseas, un rasgo aparentemente cultural es el desgaste circular o bisel que presentan algunas epífisis de huesos largos, metapodios y falanges. Sin embargo, este desgaste es efectuado por roedores que vivían próximos a la cueva, principalmente cuyes silvestres y cricétidos que eran contemporáneos a los camélidos fósiles. Los biseles formados alrededor de las fracturas transversales de huesos largos aparentemente se interpreta como herramientas óseas. Sin embargo, fueron causados por roedores que por su comportamiento de roer los bordes angulares para alisar sus incisivos hipsodontes de crecimiento continuo producen estas pseudo-herramientas.

Lumley et al. (1988) sustentan, además, el caso para la ocupación del Pleistoceno Medio de Toca da Esperança con excavaciones recientes en el estado de Piauí (sitio da Toca da Pedra Furada). La reclamada asociación del hombre y el mamut en la isla Santa Rosa, California; y los supuestos casos del Pleistoceno de Cálico han sido descartados totalmente, y casi universalmente recusados, con las asociaciones culturales y la evidencia para el fuego refutado (LYNCH, 1991b). Sin embargo, los sitios de Pedra Furada, Monte Verde, Alice Boër, Arroyo Seco e Intihuasi poseen dataciones entre 35 y 20 mil años y, por tanto, están inseridos dentro de la hipótesis PreClovis (MACNEISH; PATTERSON; BROWMAN, 1975). Pinturas rupestres, fósiles de animales extintos y material cultural se encuentran con más recurrencia contextual. Existe mayor consistencia entre la

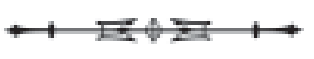


asociación hombre y mamíferos fósiles durante este período (JACOBUS, 1991; VOGEL, 1991). Un claro ejemplo de hueso trabajado se puede ver en un húmero de glossotério (oso perezoso) encontrado en el sitio Gruta dos Brejões, Bahia, que sufrió la eliminación parcial de la cabeza y una serie de cortes en la cresta deltoidea (CARTELLE, 1983) y otro hueso de équido también fue encontrado en el sitio Toca dos Búzios en el mismo Estado con señales de corte (JACOBUS, 1991). Estos ejemplos permiten tener mayor confianza de la asociación entre el hombre con los mega mamíferos fósiles durante el período entre 20.000 y 11.500 AP. Sin embargo, para las ocupaciones humanas tan remotas de 300.000 años como Toca da Esperança se debe tener todavía mayor sigilo.

Según la presencia de camélidos y otros animales herbívoros, durante el período Pleistoceno Medio, entre 295.000 e 210.000 A.P., el área de Toca da Esperança formaba parte de una extensa sabana cubierta de abundante pasto y gramíneas para la supervivencia de estos animales con alternancia de sequías e inundaciones. Es posible que este tipo de clima fresco haya continuado entre 200.000 y 17.000 años, ocurriendo períodos más fríos, lluvias torrenciales e intervalos cálidos y sequías que producían modificaciones y quemadas del ambiente tropical. Sin embargo, en el Brasil, durante aquel período no existieron glaciaciones como sucedió en los nevados de los Andes centrales y en el polo norte (AB'SABER, 1977; LYNCH, 1991a; PROUS, 1992).

Posteriormente con el cambio del ambiente a un clima más seco, ocurrió la formación caatinga, ya mencionada, que comenzó hace 17.000 AP. y paulatinamente fue avanzando hasta cubrir totalmente el área por cerca de 10.000 AP., produciendo migración y extinción de camélidos del nordeste y centro brasileño (AB'SÁBER, 1977; CARTELLE, 1983). En la Amazonía, las zonas de refugio y relictos de bosques también se expandieron modificando la fauna y flora pleistocénica por la biodiversidad moderna.
Los mamíferos fósiles de Toca da Esperança parece ser reminiscencia de la fauna de Lagoa Santa, Minas Gerais, sobreviviendo solamente en la región: el venado colorado (Mazama americana), el aguti o capibara (Agouti paca), los cávidos y cricétidos. Por otro lado, en el estado de Acre, también dos tipos de camélidos habitaban la región durante el Pleistoceno de la amazonía occidental, siendo identificados fósiles de Paleolama y de Lama vicugna (RANCY, 1993). Este dato confirma que en la región amazónica había una inmensa sabana donde convivían los armadillos grandes (Pampatherium humboldti, Propraopus sulcatus), gliptodontes (Panochthus panochthus), megaterios (Eremotherium laurillardi), mastodontes (Cuvieronius sp.), pecarís o puerco-del-mato (Tayassu pecari), tapires, toxodontes y osos perezosos. Así, la ocurrencia de sabanas en la Amazonía se alternaba con zonas de refugios forestales (AB'SABER, 1977). Esto habría producido endemismo y nuevas especies zoológicas y botánicas durante el período Cuaternario.

Finalmente, los rasgos que presentan los huesos de camélidos del sitio Toca da Esperança no parece ser fuerte evidencia para defender la presencia humana en aquel sitio durante el período Pleistoceno Medio. Sin embargo, la evidencia iconográfica de camélidos en pinturas rupestres es fuerte indicador que estos animales vivieron hasta períodos del Pleistoceno Final entre 30 y 10 mil AP. conjuntamente con la llegada de grupos humanos de cráneos dolicocéfalos del tipo Lagoa Santa, cuando los paleolamas y Lama fueron extinguidos del planalto central de Bahia.

\section{CONCLUSIONES}

El Paleolama weddeli y el Lama sp. ya estaba presentes en las cavernas calcáreas de la Toca da Esperança (Bahia, Brasil), durante el período Pleistoceno Medio, entre 295,000 y 250,000 A.P.

Los huesos de estos mamíferos no evidencian marcas o señales culturales sino de procesos tafonómicos bióticos causados por animales carnívoros, roedores

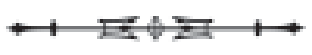


y microorganismos como hongos y líquenes, y quema durante las sequías.

La ausencia de huesos planos como el cráneo, escápula, pelvis y sacro y de paleolamas tiernos permiten sugerir dos hipótesis: ocurrió una total destrucción por los animales carnívoros y microorganismos; o debido a la humedad de la cueva y las inundaciones periódicas habrían causado destrucción de este tipo de evidencia caracterizada por su fragilidad.

El clima de aquellos tiempos era típico de sabana.

\section{AGRADECIMIENTOS}

En primer lugar agradezco a las doctoras Maria Conceição Beltrão y Martha Locks del Museu Nacional de la UFRJ que cedieron gentilmente el material para su estudio. Asimismo, a la Dra. Marli Brito M. de Albuquerque Navarro, pesquisadora e historiadora de la Fundação Oswaldo Cruz, por la corrección del texto final. Y finalmente al CNPq por la beca de estudios de doctorado entre 1996 y 2000 y a la FAPERJ por la beca parcial concedida entre 2001 y 2002.

\section{REFERENCIAS}

AB'SÁBER, A. N. 1977. Espaços ocupados pela expansão dos climas secos na América do Sul por ocasião dos períodos glaciais quaternários. Paleoclimas, São Paulo, USP, v. 3, p. 1-15.

ALTAMiRANO, A. J. 1995. Función ritual de camélidos en la costa norte: ofrendas de Pacatnamú. 285 f. Disertación (Maestría en arqueología) - Pontificia Universidad Católica del Perú, Lima.

ALTAMIRANO, A. J. 1987. Desarrollo dentario de los camélidos sudamericanos. Boletín de Lima, Lima, v. 49, p. 9-16.

BELTRÃO, M. M. C. 1993. SOS Bahia: COPA-ICOMOS-UNESCO, 16-20 de novembro. Rio de Janeiro: [s.n.]. 15 p. Mimeografiado.

BELTRÃO, M. M. C. et al. 1991. Projeto central: primeiros resultados. Recife, Universidade Federal de Pernambuco. Anais do Simpósio de Pré-história do Nordeste, revista Clio, serie arqueológica, v. 1, n. 4, p. 39-47.

BELTRÃO, M. M. C.; DANON, J. 1987. Evidence of human occupation during the middle pleistocene at the Toca da Esperanca in Central archaeological region. Anais da Academia Brasileira de Ciência, v. 3 , n. 59 , p. $275-276$.
BELTRÃO, M. M. C.; LOCKS, M. 1989. Pleistocene fauna from the "Toca da Esperanca" site (Archaeological-region of central, Bahia, Brazil): Mammals. In: CONGRESSO BRASILEIRO DE PALEONTOLOGIA, 9., Curitiba. Anais... [S.1.:s.n.]. p. 687-97.

BINFORD, L. R. 1985. Human ancestors: changing view of their behavior. Journal of Anthropological Archaeology, v. 4, p. 292-327.

BONAVIA, D. 1996. Los camélidos sudamericanos: una introducción a su estudio. Lima: IFEA-UPCH, Conservation International. $485 \mathrm{p}$.

BUSTINZA, J. A. 1970. Contribución a la diferenciación específica con los camélidos sudamericanos. In: CONVENCIÓN DE CAMÉLIDOS SUDAMERICANOS, 1., Puno. Anales... Puno, Perú: Universidad Técnica del Altiplanop. p. 27.

BUSTINZA, J. A.; MALASPINA, L. 1970. Recuento de cromosomas en la alpaca, llama y vicuña, mediante el cultivo de leucocitos de sangre periférica. In: CONVENCIÓN DE CAMÉLIDOS SUDAMERICANOS, 1., Puno. Anales... Puno, Perú: Universidad Técnica del Altiplanop. p. 21-5.

CABRERA, A. 1935. Sobre la osteología del Palaeolama. Anales del Museo Argentino de Ciencias Naturales, Buenos Aires, v. 38, p. 283-312.

CABRERA, A. 1932. Sobre los camélidos fósiles y actuales de la América Austral. Revista del Museo de La Plata, Buenos Aires, v. 33, p. 89-117.

CARTELLE, C. 1983. Tesouro fóssil no sertão baiano. Ciência Hoje, v. 1, n. 5 , p. 36-43.

COLBERT, E. H. 1955. Evolution of the vertebrates. New York: Wiley.

COPE, E. D. 1875. Systematic catalogue of vertebrate of the Eocene of New Mexico collected in 1874. Washington DC: [s.n.]. p. 1-37.

DANTAS, M. A. T. 2003. Novos táxons pleistocênicos encontrados na fazenda Elefante, Gararu, Sergipe: paleontologia em destaque. Boletim Informativo da Sociedade Brasileira de Paleontologia., v. 18, n. 44, p. 54, Out., nov./dez.

DILLEHAY, T. 1988. Early rainforest archaeology in southwestern in south america: research context, design, and data at Monte Verde'. In: PURDY, B. (Ed.). West site archaeology. New Jersey: Telford Press, Caldwell. p. 177-206.

ENCICLOPEDIA DELTA LAROUSSE. 1970. Rio de Janeiro: Editorial Koogan-Guanabara.

FAGAN, B. M. 1987. The great journey: the peopling of ancient America. London: Thames and Hudson.

FRANKLIN, W. 1982. Biology, ecology and relationship to man of the south American camelids. In: MARES, M. A; GENOWAYS, H. H. (Ed.). Mammalian biology of South America. Pittsburgh: [s.n.]. p. 457-489.

GERVAIS, H. ; AMEGHINO, F. 1880. Les mammiferes fossiles de l'Amerique du Sud. Paris: [s.n.]. p. 114-212.

GERVAIS, H. 1855. Recherche sur les mamiferes fossiles de l'Amerique meridionale. Paris: [s.n.]. p. 40-43. v. 30.

GOMIDE, M. S. 1999. Sistematização de critérios para diagnóstico diferencial entre Paleopatologias e sinais de alterações análogas: fundamentos teórico-metodológicos, R.J. Tese (Doutorado em saúde pública) - ENSP, Fiocruz.

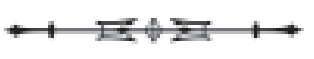


GRAYSON, D. K. 1983. On the methodology of faunal remains. American antiquity, v. 38, n. 34, p. 432-39.

GUERIN, C.; FAURE, M. 1999. Palaeolama (Hemiauchenia) niedae nov. Sp., nouveau Camelidade du Nordeste Brasilien, et sa place parmi les Lamini d'Amérique du Sud. Goebios, Lyon, v. 32, n. 12, p. 629-659, il.

GUIDON, N. 1984. As primeiras ocupações humanas da área arqueológica de São Raimondo Nonato. Revista de Arqueologia Belém, v. 2, n. 1, p. 38-46.

GUIDON, N. 1988. On stratigraphy and chronology at Pedra Furada. Current Anthropology, v. 30, p. 641-2.

HERRE, W. 1952. Studien uber die widen und domestizierten Tilopoden sud-amerikas. Berlin Zoologisches Garten, v. 19 , n. 2-4, p. 20-98.

HOFFSTETTER, R. 1952. Les mamiferes pleistocenes de la republique de l'Equateur. Memorias de la Sociedad Geológica de France., Nouvelle-series, Paris, v. 66, n. 31, p. 1-4.

JACOBUS, A. L. 1991. Os homens e a fauna extinta. Anais Simpósio de Pré-história do Nordeste, revista Clio, v. 4, n. 1, p. 29-30.

LÓPEZ ARANGUREN, D. J. 1930. Camélidos fósiles argentinos. Buenos Aires: Anales de la Sociedad Científica Argentina. p. 2-216. v. 109.

LUMLEY, H. et al. 1988. Decouverte d'Outils taillés associes a dês faunes du pleistocene moyen dans la Toca da Esperança, État de Bahia, Brésil. Cr. Acad. Sciences de Paris, Paris, v. 306, n. 2, p. 241-247.

LYNCH, T. F. 1991a. Lack of evidence for glacial-age settlement of South America: replay to Dillehay and Collins and to Gruhn and Bryan. American Antiquity, v. 56, n. 2, p. 348-355.

LYNCH, T. F. 1991 b. The peopling of the Americas - a discussion. In: DILLEHAY, T. D.; MELTZER, D. J. The first Americans. [S.1.]: Academic Press. p. 267-74. chapter 10.

MACNEISH, R.; PATTERSON, T.; BROWMAN, D. 1975. The central Peruvian prehistoric interaction sphere. Papers of the Robert $\mathrm{S}$. Peabody foundation for archaeology, Andover, v. 7.
PACHECO, V. R.; ALTAMiRANO, A. J.; GUeRRA, E. 1986. The Osteology of the south american camelids. Los Angeles, California: University of Los Angeles, CA. 32 p. v. 1.

PAULA COUTO, C. 1979. Tratado de Paleomastozoologia. Rio de Janeiro: Academia Brasileira de Ciências. 590 p.

PIRES-FERREIRA, E. 1982. Nomenclatura y nueva clasificación de los camélidos sudamericanos. Revista do Museu Paulista, São Paulo, v. 28, p. 203-219.

PROUS, A. 1992. Arqueologia Brasileira. Brasília, DF: Editora Universidade de Brasilia. $605 \mathrm{p}$.

RANCY, A. 1993. Mamíferos fósseis. A paleofauna da amazônia indica áreas de pastagem com pouca cobertura vegetal. Ciência Hoje, Rio de Janeiro, v. 16, n. 93, p. 48-51.

SANDERS, W. T.; MARINO, J. 1971. Pré-história do novo mundo: arqueologia do índio americano. Rio de Janeiro: Zahar Editores. Curso de antropologia moderna.

SIMPSON, G. G. 1945. The principles of classifications and a classification of mammals. American Bulletin of Museum Natural History, v. 85, n. 26, 350 p.

STANLEY, H. F.; KADWELL, M.; WHEELER, J. 2000. ARTIGO. Disponível em: <http//mww.visionveterinaria.com/prion/Camelidae.html>. SUMAR, J. K. 1992. Los camélidos domésticos en el Perú. Lima. Boletin de Lima, v. 79, p. 81-95.

VALLENAS, A. P. 1970. Comentarios sobre la posición de los camélidos sudamericanos en la sistemática. Boletín extraordinario del IVTA, Lima, Universidad Nacional Mayor de San Marcos, v. 4, p. 126-41.

VOGEL, M. A. C. 1991. A megafauna do sudeste de Piauí. Anais Simpósio de Pré-história do Nordeste, revista Clio, v. 4, n. 1 , p. 23.

WEBB, D. S. 1974. Pleistocene llamas of Florida, with brief review of the Lamini. In: WEBB, D. S. (Ed.). Pleistocene Mammals of Florida. Gainesville: University of Florida Press. p. 170-213.

WHEELER, J. 2000. Disponível em: <http://www.rmla.com/ origin_of_sa_camelids.htm>, <http://www.acnatsci.org/museum/ leidy/paleo/poebrotherium.html $>$ 
Los camelidos fosiles del sitio Toca da Esperança, Bahia, Brasil

ANEXO 1. Relación de huesos de camélidos de Toca da Esperança. rabajo realizado en el Museu Nacional, UFRJ, del 21 de mayo al 11 de junio de1997.

Capa III, No reg. 019 - Vértebra lumbar, 6a o 7a L, cuerpo vertebral, fracturado severamente y quemado natural. Paleolama adulto, mayor de 5 años, robusto, tejido óseo osteoporoso, borde ventral também en forma longitudinal.

Capa IV, No reg. 040 - Metacarpiano izquierdo fragmentado, epíisisis distal, de Paleolama major de adulto mayor de 5 años. Ennegrecido y fracturado.

Capa IV, No reg. 041 - Metacarpiano, epíísis proximal fragmentado, de camélido robusto, adulto mayor de 5 años, se observa el tejido óseo osteoporoso.

Capa IV, No reg. 042 - Húmero distal, lado izquierdo, fragmentado, fracturas transveral antero-posterior y borde condíleo, tejido óseo esponjoso, homogeneo, propio de camelidos cerca al mar (tropical y litoral), pieza robusta adulta. Ennegrecido (tiene dibujo).

Capa IV, No reg. 043 - Tercer carpiano izquierdo de camélido robusto, adulto mayor de 5 años, completo de color amarillento con hongos y liquenes.

Capa N, No reg. 044 - Tercer carpiano fragmentado, esta asociado con el 041, de camélido robusto, adulto mayor de 5 años, mas este es otro individuo. Fractura y ennegrecido por hongos y liquenes.

Capa IV, No reg. 045 - Fémur derecho, epífisis distal fragmentado, quemado, fractura transversal com mordeduras de carnívoros. Tejido óseo poroso y homogeneo de camélido adaptado a zonas bajas, robusto y subadulto (4-5 años).

Capa IV, No reg. 047 - Metacarpiano, parte distal, de camélido robusto subadulto de 3-4 años. Tamaño de una llama. Asociado con restos hongos y liquenes.

Capa IV, 048 - Epífisis distal de húmero izquierdo de paleolama adulto mayor de 5 años, fractura y mordido por carnívoros, ennegrecido por hongos y liquenes que produjo oxido de manganeso por extrema humedad en suelo calcáreo (tiene dibujo).

Capa IV, No reg. 049 - Primer carpiano de camélido robusto, ixquierdo, adulto y mordido por carnivoros.

Capa IV, No reg. 050 - Primera o segunda falange, epífisis distal, fragmentado, fractura transversal y angular, se parece al del 056, posiblemente para extraer la medula de patas. Paleolama joven de 2-3 años. Este patrón de fractura se repite a los otros 050, 56, 66 y 77.

Capa IV, No reg. 051 - Segundo carpiano derecho, completo, paleolama adulto o joven, también ennegrecido. Esta asociado con el 058.

Capa IN, No reg. 052 - Húmero proximal, fragmentado, com ligera mancha de quemado, subadulto de 4-5 años. Animal robusto. Posee ampla fosa poplítea, coloración marrón-rojizo. Lado izquierdo, consumido por carnivoros.

Capa IV, No reg. 053 - Diente molar selenodonte, superior derecho, Lama joven de 1-3 años, com fragmento de maxilar, calcinado, posee las cuspides completas y raíz abierta. Tamaño menor de llama. Este fragmento es parte del 067.

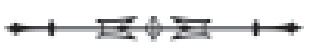


Capa N, No reg. 055 - Segundo molar fragmentado de color blanco y corazón negro (quema), indica fuerte quemada de los arbustos, cuspide y columna, de Paleolama joven de menos de 2 años.

Capa IV, No reg. 056 - Primera falange completo, tuvo uma fractura a nível de la diafisis, y presión de la epifisis distal, color rojizo-ladrillo y ennegrecido por quemadura. Pieza de camélido robusto, adulto mayor de 5 años.

Capa IV, No reg. 058 - Segundo carpiano izquierdo, escafoide completo, paleolama adulto o joven, con líquenes que produjeron las manchas oscuras, incluye hongos.

Capa I, No reg. 059 - Epífisis distal de metatarsiano izq. con fractura transversal de Paleolama major de adulto mayor de 5 años. Ennegrecido y fracturado.

Capa IV, No reg. 062 - Segundo carpiano completo, semilunar, lado izquierdo de camélido robusto de tamaño de llama, adulto mayor de 5 años. Calcinado.

Capa N, No reg. 063 - Calcáneo derecho fragmentado de camélido robusto, adulto mayor de 5 años, borde articular con astrágalo. Fractura transversal.

Capa IV, No reg. 064 - Maleolo lateral completo lado izquierdo de camélido robusto, adulto mayor de 5 años, asociado a la pieza anterior 063, parece ser del mismo individuo.

Capa IN, No reg. 065 - Tercer molar inferior derecho de Paleolama adulto mayor de 8 años, cara oclusal muy desgastada, se presenta la raíz antero-mesial y distal.

Capa N, No reg. 067 - Diente molar selenodonte, superior derecho, Lama joven de 1-3 años, com fragmento de maxilar, calcinado, posee las cuspides completas y raíz abierta. Tamaño menor de llama.

Capa IN, No reg. 068 - Axis, segunda vertebra cervical fragmentada, paleolama, adulto mayor de 8 años, apófisis adontoides fracturado por carnívoros. Paleolama adulto mayor de 8 años, apresenta ennegrecido por óxido de manganeso dos hongos y liquenes por humedad.

Capa IV, No reg. 069 - Cuarto tarsiano o cuboide izquierdo, completo, blanco por calcáreo y fondo marrón y negro por quemada. adulto mayor de 5 años y robusto.

Capa IV, No reg. 070 - Vértebra cervical 2a o $3^{\mathrm{a}}$ apófisis articular posterior y facteas mamilares, color rojizo, con manchas ennegrecidas y marrón, Puede haber sido fractura por mordedura. Animal adulto.

Capa IV, No reg. 077 - Primera falange, epifisis distal de camélido robusto, subadulto de 3-4 años, fragmentado por fractura transversal antero-posterior, biconconcoidal, para extracción de médula.

Capa IV, No reg. 081 - Astrágalo izquierdo completo de paleolama subadulto de 3-4 años, ligeramente fracturado (existe dibujo).

Capa IV, No reg. 082 - Astrágalo derecho fragmentado de paleolama subadulto de 3-4 años, ligeramente fracturado.

Capa N, No reg. 085 - Tercer molar, inferior derecho de camélido robusto (paleolama) adulto mayor de 5 años, fragmentado, calcinado sin raíz.

Capa IV, No reg. 086 - Segundo molar fragmentado de color blanquecina y corazón negro (quema) de Paleolama major de joven mayor de 3 años. Ennegrecido y fracturado.

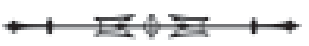


Capa N, No reg. 087 - Escápula derecha fragmentada, parte de la tuberosidad de la escápula y apófisis coracóides de Paleolama major de adulto mayor de 5 años. Ennegrecido por quema y fracturado por mordidas.

Capa IN, No reg. 088 - Epífisis distal de húmero com fractura transversal y angular, fragmentado, de Paleolama major de adulto mayor de 5 años. Ennegrecido por extremo calor (quema) y extrema humedad (hongos y liquenes).

Capa IV, No reg. 089 - Epífisis distal de metatarsiano con fractura transversal y angular, ennegrecido por quema (extremo calor), y después por hongos y liquenes (extrema humedad). Paleolama major de adulto mayor de 5 años.

Capa N, No reg. 090 - Epífisis distal de metacarpiano con fractura transversal y angular de Paleolama major de adulto mayor de 5 años. Ennegrecido por liquenes y hongos. Presenta desgaste del borde de forma de bisel hecho por roedores (preá) o cricétidos.

Capa IV, No reg. 091 - Puede ser tarsiano, carpiano o metapodio, la identificación de paleolama es dudosa, fragmentado.

Capa IV, Nº reg. 092 - El diente está relacionado con el 054. Primer o segundo molar superior fragmentado de color blanco, tetra-radicular, selenodonte par, de Paleolama major adulto mayor de 5 años.

Capa IN, No reg. 103 - Epífisis distal de metatarsiano con fractura transversal de Paleolama major de adulto mayor de 5 años. Ennegrecido por liquenes y hongos.

Capa IV, No reg. 104 - Tibia derecha fragmentado, epífisis distal no fusionado, paleolama joven de 2-3 años. Incinerado y fracturado.

Capa IV, No reg. 106 - Epífisis distal de húmero izquierdo de fractura transversal y angular, ennegrecido por extrema humedad, liquenes y hongos. De Paleolama adulto (tiene dibujo).

Capa IV, No reg. 117 - Astrágalo derecho completo con clara evidência de mordida de carnívoros, felino o canido, antero-posterior, ennegrecido por hongos y liquenes que produjo oxido de manganeso por extrema humedad en suelo calcáreo. paleolama adulto mayor de 5 años (tiene dibujo).

Capa N, No reg. 119 - Epífisis proximal de fémur derecho parte de la cabeza para su inserción con pelvis, tejido óseo homogéneo, fracturado por severa mordedura de animales carnívoros, de Paleolama major de joven menor de 4 años. Ennegrecido por extrema humedad (hongos y liquenes).

Capa I, No reg. 123 - Epífisis distal de metacarpiano de paleolama subadulto, mordido por animales carnívoros, impregando por suelo calcáreo, humedad y ennegrecido por hongos y liquenes que produjeron óxido de manganeso.

Capa IV, No reg. 124 - Epífisis distal de metacarpiano de paleolama subadulto, mordido por animales carnívoros, impregando por suelo calcáreo, humedad y ennegrecido por hongos y liquenes que produjeron óxido de manganeso.

Capa IV, No reg. 136 - Maleolo lateral derecho de camélido robusto, adulto mayor de 5 años, completo, color marrón-rojizo. Tamaño mayor de una llama actual.

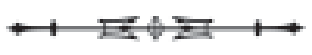

